\title{
Demographic characteristics of elite Kenyan endurance runners
}

\author{
VINCENT O. ONYWERA ${ }^{1}$, ROBERT A. SCOTT ${ }^{2}$, MICHAEL K. BOIT ${ }^{1}, \&$ \\ YANNIS P. PITSILADIS ${ }^{1,2}$ \\ ${ }^{1}$ Department of Exercise and Sports Science, Kenyatta University, Nairobi, Kenya, and ${ }^{2}$ International Centre for East African \\ Running Science, Institute of Biomedical and Life Sciences, University of Glasgow, Glasgow, UK
}

(Accepted 20 May 2005)

\begin{abstract}
Kenyan athletes have dominated international distance running in recent years. Explanations for their success include favourable physiological characteristics, which could include favourable genetic endowment, and advantageous environmental conditions. The aim of this study was to compare the demographic characteristics of elite Kenyan runners with those of the general Kenyan population. Questionnaires, administered to 404 elite Kenyan runners specializing in distances ranging from the $800 \mathrm{~m}$ to the marathon and 87 Kenyan controls, obtained information on place of birth, language, and distance and method of travel to school. Athletes were separated into two groups according to athletic success: those who competed in international competition and those who competed in national competition. The athletes differed from controls in regional distribution, language, and distance and method of travel to school; athletes also differed from each other with the exception of method of travel to school. Most national and international athletes came from the Rift Valley province (controls $20 \%$, national athletes $65 \%$, international athletes $81 \%$ ), belonged to the Kalenjin ethnic group (controls $8 \%$, national athletes $49 \%$, international athletes $76 \%$ ) and Nandi sub-tribe (controls $5 \%$, national athletes $25 \%$, international athletes $44 \%$ ), and spoke languages of Nilotic origin (controls $21 \%$, national athletes $60 \%$, international athletes $79 \%$ ). A higher proportion of all athletes ran to school each day (controls $22 \%$, national athletes $73 \%$, international athletes $81 \%$ ) and covered greater distances. In conclusion, Kenyan runners are from a distinctive environmental background in terms of geographical distribution, ethnicity and travelled further to school, mostly by running. These findings highlight the importance of environmental and social factors in the success of Kenyan runners.
\end{abstract}

Keywords: Athletes, demographics, endurance, environment, Kenya

\section{Introduction}

Since the Mexico Olympics, East African runners have enjoyed unparalleled success in distance running events ranging from the $800 \mathrm{~m}$ to the marathon. Apart from dominating the Olympic middle- and long-distance track events, Kenyan and Ethiopian athletes have also dominated the world cross-country and road-racing circuit. For example, more than $50 \%$ of the all-time top 20 performances for men in these distances have been performed by Kenyan athletes. Ethiopian runners, on the other hand, won 24 of 54 possible World Championship medals for distance running events since the 2001 World IAAF Championships in Edmonton up until Helsinki 2005. Several studies have attempted to explain the success of East African runners. Proposed explanations have included environmental factors (Saltin, 1996; Scott et al., 2003), psychological advantage (Baker \&
Horton, 2003) and favourable physiological characteristics that could be genetically conferred or environmentally determined (for a review, see Larsen, 2003). Some studies have also compared the physiological characteristics of "black" and "white" runners, reporting for the former lower blood and muscle lactate concentrations at a given exercise intensity (Coetzer et al., 1993; Saltin et al., 1995; Weston, Karamizrak, Smith, Noakes, Myburgh, 1999), better running economy (Saltin et al., 1995; Weston, Mbambo, \& Myburgh, 2000) and an ability to tolerate higher fractional utilization of maximal oxygen uptake $\left(\dot{V} \mathrm{O}_{2 \max }\right)$ (Bosch, Goslin, Noakes, \& Dennis, 1990; Coetzer et al., 1993; Weston et al., 2000). However, the validity of extrapolating such findings to account for the success of East African athletes is questionable when participants have been classified into groups based primarily on skin colour, given that there are more genetic differences within

Correspondence: Y. P. Pitsiladis, ICEARS, Institute of Biomedical and Life Sciences, West Medical Building, University of Glasgow, Glasgow G12 8QQ, UK. E-mail: y.pitsiladis@bio.gla.ac.uk 
"race" groups than between them (Yu et al., 2002). Although "performance genes" have been identified as being important in elite sporting performance (Gayagay et al., 1998; Yang et al., 2003), no direct genetic evidence has been found to account for the success of East African runners.

Factors such as altitude and distance travelled to school each day have also been proposed to account partially for the success of East African runners (Saltin, 1996; Scott et al., 2003). Although equivocal, some studies have concluded that chronic altitude exposure and endurance training, as experienced by many East African runners, combine synergistically to induce haematological adaptations which partially account for their success (Schmidt et al., 2002). A high proportion of elite Ethiopian runners originate from particularly altitudinous regions of Ethiopia (Scott et al., 2003), although this was not necessarily causal to their success. In this study in Ethiopia, a higher proportion of the Ethiopian runners travelled long distances to school each day by running compared with controls (Scott et al., 2003). It has previously been shown that Kenyan boys who travelled to school by walking and running had a $30 \%$ higher $\dot{V} \mathrm{O}_{2 \max }$ than those who did not (Saltin et al., 1995). Such findings support anecdotal suggestions that running long distances to school each day influences the success of East African runners.

Kenya is the model for the current study as its athletes have an unparalleled record of success in international distance running competition (Larsen, 2003). Kenya has a population of approximately 30 million, distributed among eight provinces, and is peopled by three main language groups: Bantu, Nilotic and Cushitic. The largest of these groups is the Bantu, who account for approximately $65 \%$ of the Kenyan population. Nilotic speakers account for approximately $25 \%$ of the population and include the Kalenjin, who produce a disproportionately large number of elite Kenyan runners (Manners, 1997). The Kalenjin have a population of approximately 3 million, about $10 \%$ of the Kenyan population, yet have won about $75 \%$ of all major distance running races in Kenya (Manners, 1997). Internationally, Kalenjin runners have won $73 \%$ of all Kenyan gold medals and a similar percentage of silver medals at major international running competitions. To our knowledge, no study has attempted to trace the ethnic or environmental background of elite Kenyan runners and, by doing so, examine the possibility that they might share a common ethnic or environmental origin and possibly some form of homogeneity in comparison with the general population. The aim of this study, therefore, was to determine the ethnic and environmental background of elite Kenyan runners. The findings were then compared to the general "nonathlete" Kenyan population to identify whether the athletes were of a distinct ethnic or environmental background.

\section{Methods}

A total of 491 participants provided written informed consent before taking part in the study, which was approved by the university ethics committee and local Kenyan authorities in Nairobi. Participants comprised 404 athletes, of whom many had won Olympic and Commonwealth medals as well as participated in major world marathons, and 87 controls. Both athletes and controls comprised males and females. The control group, who were students at Kenyatta University in Nairobi, were representative of the Kenyan general population in their regional origins; none were regularly training for any track or field athletic events.

The athletes were classified into one of two groups according to athletic success: international athletes $(n=97)$, who had represented Kenya at international events such as the Olympic games, Commonwealth games, All-African Games or in international marathon events, and national athletes $(n=307)$, who were active in national competition in Kenya but without any major international distinctions. International athletes comprised many of the most successful Kenyan runners of all time, including many World and Olympic champions, as well as athletes who have represented Kenya in other major international events and marathon races. Athletes specialized in distances ranging from the $800 \mathrm{~m}$ to the marathon.

\section{Questionnaires}

Questionnaires were administered to all individuals participating in this study. The questions were designed to obtain the following information:

Place of birth. This was classified according to the eight provinces of Kenya (Kenyan Central Bureau of Statistics, 2003). Our intention was to identify particular regions with a disproportionately high number of athletes in response to reports that the majority of the most successful Kenyan runners are from one altitudinous region of Kenya (i.e. Nandi District, Figure 1) (Manners, 1997). The regional distribution of the control group was also compared with that of the Kenyan population (Kenyan Central Bureau of Statistics, 2003).

Spoken language (and that of their grandparents). This was to provide further information on ethnicity. A common language can be indicative of common 


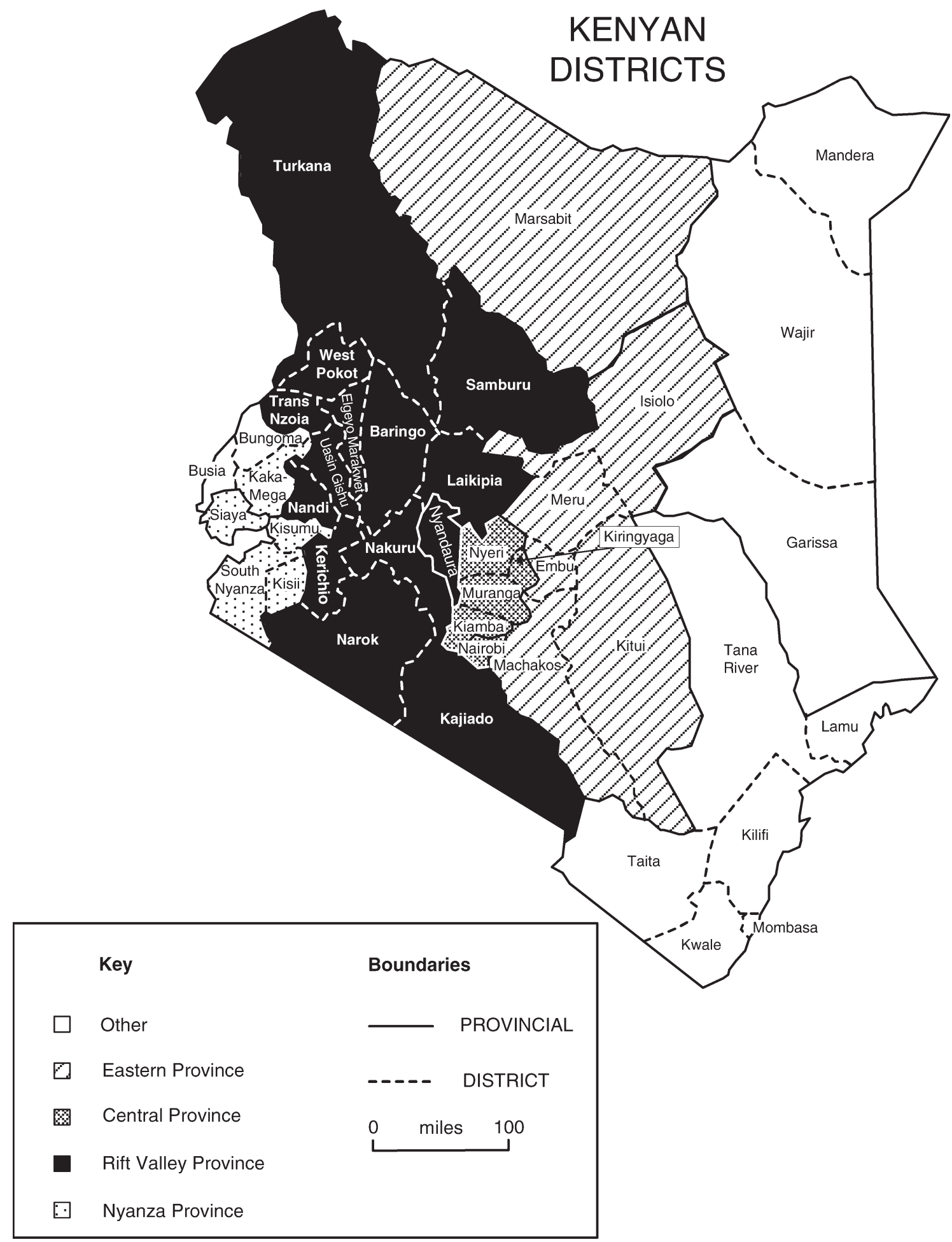

Figure 1. Districts of Kenya reflecting distribution of participants in the present study. "Other" covers Coast, North-Eastern and Western provinces.

origin, and a related language (i.e. a language of the same family) can also suggest a common origin, but one that is older. Currently, Kenya has 42 ethnic groups, who speak languages belonging to one of the following three language subsets: Bantu, Nilotic or
Cushitic. It is estimated that these language categories are spoken by approximately $65 \%, 30 \%$ and $2 \%$ of the Kenyan population, respectively; the remaining small proportion being languages of European or other origin (Pkalya \& Aden, 2003). 
Distance travelled $(<5 \mathrm{~km}, 5-10 \mathrm{~km},>10 \mathrm{~km})$ and mode of travel (walk, run, other) to school. We wished to determine how far the athletes travelled to school and the mode of transport they used. This was to assess the influence of running long distances to school each day on East African running success.

\section{Data analysis}

Contingency chi-square tests were performed to identify frequency differences between groups (place of birth: degrees of freedom [d.f.] =10; language group: d.f. $=2$; ethnicity: d.f. $=16$; distance and method of travel to school: d.f. $=4$ ). Individual chisquares were then determined to identify between which groups the differences lay (place of birth: d.f. $=5$; language: d.f. $=1$; ethicity; $d . f=8$; distance and method of travel to school: d.f. $=2$ ). Statistical significance was declared at $P \leqslant 0.05$. In Figure 2, Nairobi, Coast, Western and North Eastern provinces, which collectively accounted for less than $9 \%$ of all participants, were collapsed into "Other" to allow statistical analysis. In Figure 4, the ethnic communities that accounted for less than $5 \%$ of all participants were also collapsed into "Other".

\section{Results}

Place of birth. The regional distribution of the controls did not differ from that of the Kenyan population $\left(\chi^{2}=5.7, P=0.23\right)$ based on recent census data (Kenyan Central Bureau of Statistics, 2003) but differed both from national $\left(\chi^{2}=85\right.$, $P<0.001)$ and international $\left(\chi^{2}=84, P<0.001\right)$ runners (Figure 2). Both national and international groups displayed a marked over-representation of athletes from the Rift Valley province (controls $20 \%$, national athletes $65 \%$, international athletes $82 \%$ ). National athletes also differed from international athletes $\left(\chi^{2}=12, P=0.019\right)$ (Figure 2$)$.

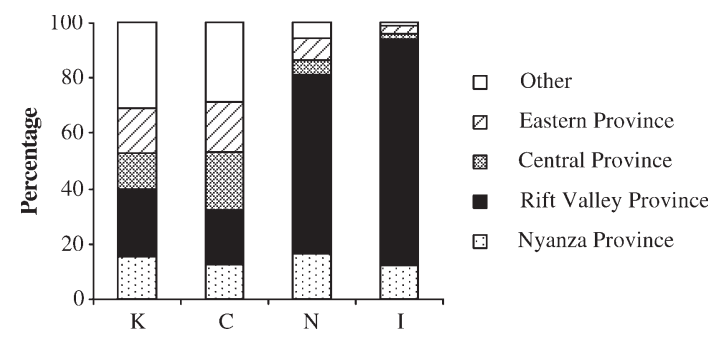

Figure 2. Regional distribution of subject groups and Kenyan population (K). Regional distribution of controls (C) did not differ from the Kenyan population $(P=0.23)$, but differed from both national $(\mathrm{N} ; P<0.001)$ and international athletes $(\mathrm{I} ; P=0.001)$. National athletes also differed from international athletes $(P=0.022)$.
Language. The origin of language of control participants differed from that of national $\left(\chi^{2}=42\right.$, $P<0.001)$ and international $\left(\chi^{2}=63, P<0.001\right)$ athletes, with both athlete groups showing a predominance of languages of Nilotic origin compared with controls (controls $21 \%$, national athletes $60 \%$, international athletes 79\%) (Figure 3). National athletes also differed from international athletes $\left(\chi^{2}=12, P<0.001\right)$ (Figure 3).

Ethnicity. The language spoken by controls differed from that of national $\left(\chi^{2}=73, P<0.001\right)$ and international $\left(\chi^{2}=112, P<0.001\right)$ athletes (Figure 4$)$. National athletes also differed in spoken language from international athletes $\left(\chi^{2}=34, P<0.001\right)$.

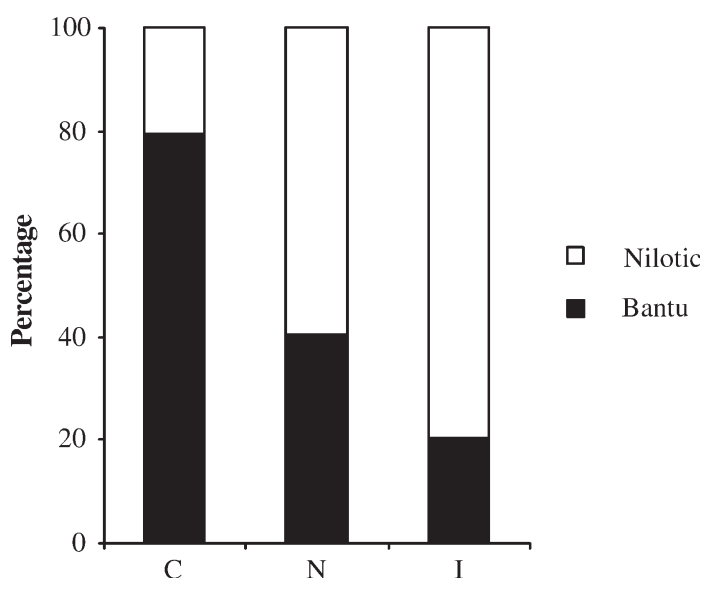

Figure 3. Language group distributions. Percentage of participants' grandparents speaking languages of each origin is shown. Language group distributions of all groups differed from each other (C vs. N: $P<0.001$; C vs. I: $P<0.001$; I vs. C: $P<0.001$ ). $\mathrm{C}=$ controls, $\mathrm{N}=$ national athletes, $\mathrm{I}=$ international athletes.

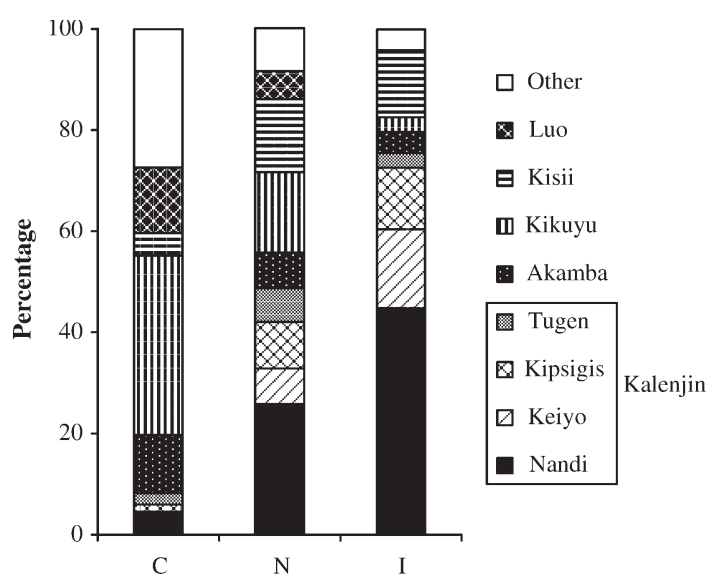

Figure 4. Ethnicity of participant groups. Percentage of participants by ethnicity is shown. Ethnicity distributions of all the groups differed from each other (C vs. N: $P<0.001$; C vs. I: $P<0.001$; I vs. C: $P<0.001)$. $\mathrm{C}=$ controls, $\mathrm{N}=$ national athletes, $\mathrm{I}=$ international athletes. 
Both athlete groups showed an over-representation of Kalenjin athletes (controls $8 \%$, national athletes $49 \%$, international athletes $75 \%$ ), especially from the Nandi sub-tribe (controls 5\%, national athletes $26 \%$, international athletes $44 \%$ ). Nandi is a district in Kenya accounting for less than 3\% of the Kenyan population (Kenyan Central Bureau of Statistics, 2003).

Distance travelled to school. For distance travelled to school, control participants differed from both national $\left(\chi^{2}=9, P=0.01\right)$ and international $\left(\chi^{2}=.13\right.$, $P=0.002$ ) athletes (Figure 5). National athletes also differed from international athletes in distance travelled to school $(\chi=12, P=0.020)$. Seventy-five percent of controls travelled less than $5 \mathrm{~km}$ to school each day, compared with $58 \%$ of national athletes and $49 \%$ of international athletes (Figure 5). Of the international athletes, $23 \%$ travelled further than $10 \mathrm{~km}$ to school each day, compared with $11 \%$ of the national athletes and $9 \%$ of the controls (Figure 5).

Method of travel to school. For method of travel to school, controls differed from national $\left(\chi^{2}=75\right.$, $P<0.001)$ and international $\left(\chi^{2}=66, P<0.001\right)$ athletes; a higher proportion of athletes ran to school each day (controls $22 \%$, national athletes $73 \%$, international athletes 81\%) (Figure 6). National athletes did not differ from international athletes in method of travel to school $\left(\chi^{2}=3.1, P=0.22\right)$. Groups also differed in their method of travel to school when travelling equivalent distances. Although similar proportions of controls and athletes travelled more than $5 \mathrm{~km}$ to school each day (Figure 5), only 23\% of the 22 controls (who travelled further than $5 \mathrm{~km}$ each day) ran to school, $23 \%$ walked and $54 \%$ used another form of transport. However, among the athletes who travelled further than $5 \mathrm{~km}$ each day, the overwhelming majority ran to school $(77 \%$ of the 130 national athletes and $86 \%$ of the 49 international athletes; controls vs. national athletes: $\chi^{2}=35.2, P<0.001$; controls vs. international athletes: $\chi^{2}=28.5, P<$ $0.001)$. However, it is worth noting that $54 \%$ of the controls who travelled further than $5 \mathrm{~km}$ to school each day used means of transport other than walking or running, compared with only $8 \%$ and $6 \%$ of national and international athletes, respectively. When participants using other means of getting to school, such as a bicycle or motorized transport, were excluded from all three groups, the differences in running to school between groups remained, with $50 \%$ of controls $(N=10), 84 \%$ of national $(n=119)$ and $91 \%$ of international $(n=46)$ athletes running to school (controls vs. National athletes: $\chi^{2}=7.10$, $P=0.008$; controls vs. international athletes: $\left.\chi^{2}=10.39, P=0.001\right)$.

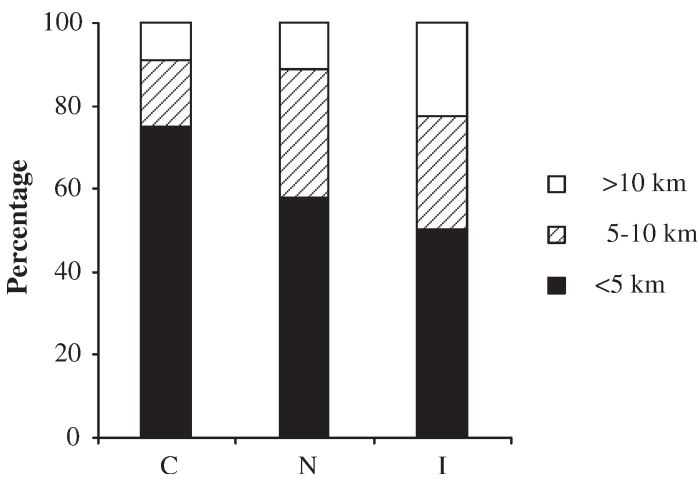

Figure 5. Distance travelled to school. The percentage of participants travelling each distance to school is shown. All groups differed from each other (C vs. N: $P=0.01$; C vs. I: $P=0.002$; I vs. $\mathrm{C}: \mathrm{P}=0.020) . \mathrm{C}=$ controls, $\mathrm{N}=$ national athletes, $\mathrm{I}=$ international athletes.

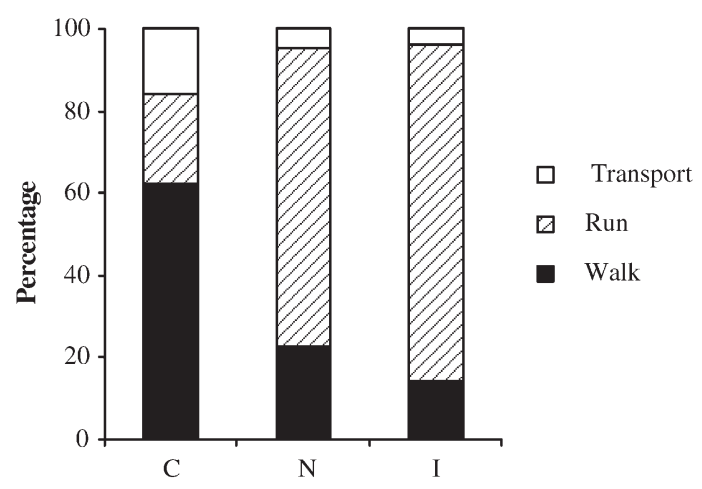

Figure 6. Method of travel to school. The percentage of participants using each method of travel to school is shown. Controls differed from both athlete groups $(\mathrm{N}: P<0.001$; I: $P<0.001)$. National $(\mathrm{N})$ and international (I) athletes did not differ in their distribution $(P=0.22)$.

Motivation to become a competitive athlete. The motivation of Kenyan national and international athletes to become a competitive athlete was similar $\left(\chi^{2}=6.6, P=0.36\right)$ (Figure 7). Both national $(39 \%)$ and international $(34 \%)$ athletes declared economic reasons. Typically, Kenyan athletes see athletics as a means of making money to help their families, parents and siblings.

\section{Discussion}

The findings of this study show that Kenyan athletes, particularly the international athletes, are of a distinct environmental and ethnic background. Both the national and international athlete groups differed from the control group in all categories that were considered. Sixty-five percent of national athletes and $81 \%$ of international athletes were from the Rift Valley province, in contrast to control participants, of whom only $20 \%$ were from the Rift Valley province. 
National

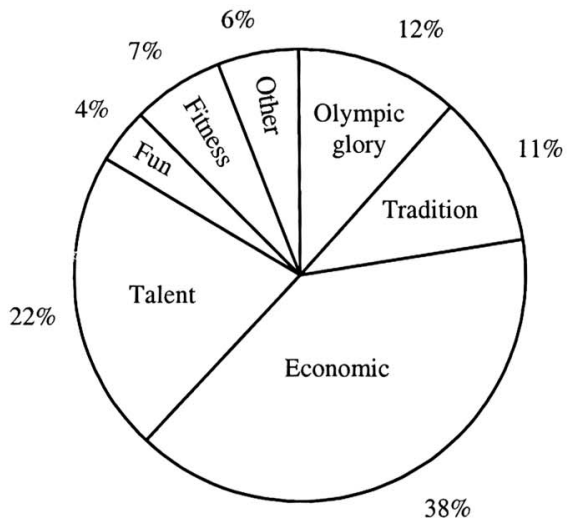

International

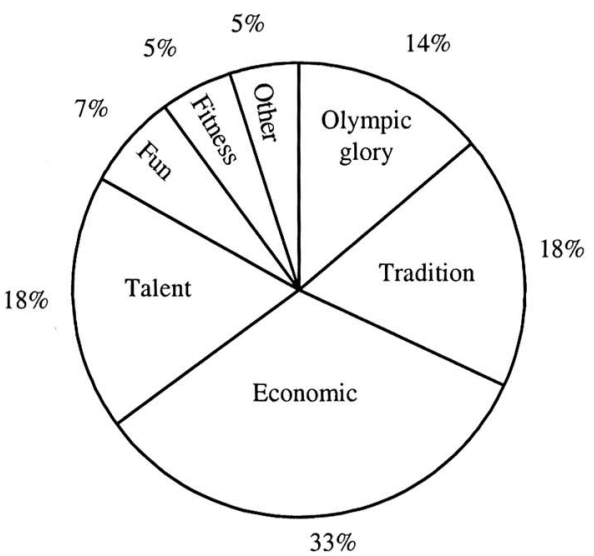

Figure 7. Motivation to become a competitive athlete. Both athlete groups showed similar reasons for becoming a competitive athlete $(P=0.36)$, with economic motivation most prevalent.

For language group, there is a gradation of results from controls to national and international athletes: $79 \%$ of international athletes speak languages of Nilotic origin compared with $60 \%$ of national athletes and only $21 \%$ of control participants. It was also found that a higher proportion of athletes travelled farther than $5 \mathrm{~km}$ to school than controls (controls $25 \%$, national athletes $42 \%, P=0.01$; international athletes $51 \%, P=0.002$ ) and a higher proportion of athletes travelled these distances by running [controls $22 \%$; national athletes $73 \%(P<0.001)$; international athletes $81 \%(P<0.001)]$. These findings highlight the importance of environmental factors in the selection of elite Kenyan athletes.

As can be seen in Figure 2, the control group has a similar regional distribution to the Kenyan population. However, both athlete groups show a distinct distribution with an over-representation from the Rift Valley province. Of the international athletes, for the most successful Kenyan athletes of past and present $81 \%$ were from this region, which accounts for less than a quarter of the Kenyan population (Kenyan Central Bureau of Statistics, 2003). The over-representation from the Rift Valley mirrors previous findings in elite Ethiopian marathon athletes, where $73 \%$ were from the Arsi and Shewa regions proximal to the Rift Valley. Regions proximal to the Rift Valley often lie at altitudes of over $2000 \mathrm{~m}$ above sea level, which might be haematologically beneficial in distance running (Schmidt et al., 2002). These findings support suggestions that the success of Kenyan runners is in some way linked to their close proximity to the Rift Valley (Entine, 2001).

A higher proportion of athletes, particularly international athletes, spoke languages of Nilotic origin compared with controls (controls vs. national athletes: $P<0.001$; controls vs. international athletes: $P<0.001$ ) (Figure 3). This is considered to be a reflection of the geographical distribution of the athletes and the peopling of the Rift Valley province, which is primarily populated by people speaking languages of Nilotic origin. In Ethiopian athletes, it was found that a higher proportion of marathon athletes spoke languages of Cushitic origin than controls $(P<0.001)$. In Kenya, languages of Cushitic origin account for less than $10 \%$ of spoken languages and, as such, no participants in this study spoke languages of Cushitic origin. When the ethnicity of athletes was compared with that of controls, there was an excess of athletes belonging to the Kalenjin tribe (Figure 4) [controls 8\%; national athletes $49 \% \quad(P<0.001)$; international athletes $75 \%(P<0.001)]$. This imbalance of elite Kenyan athletes has been attributed to cultural factors within the Kalenjin tribe, where the success of Kipchoge Keino, the most famous Kenyan runner, is thought to have spurred on a tradition of distance running that is now augmented by talent recruitment to high schools with formal training and competition (Saltin et al., 1995). As can be seen in Figure 4, many of the national and international athletes belong to the Nandi sub-tribe (controls 5\%, national athletes 26\%, international athletes $44 \%$ ), yet the Nandi region accounts for only $3 \%$ of the total Kenyan population. Again, cultural factors could be important here, as many of the most successful Kenyan athletes have belonged to the Nandi. The fame and fortune afforded to these runners could inspire young Nandi people to adopt distance running as a potential career.

In this study, a higher proportion of international $(51 \%, P<0.002)$ and national athletes $(42 \%$, $P<0.01)$ travelled farther than $5 \mathrm{~km}$ to school each 
day than controls (25\%) (Figure 5). Although mirrored in Ethiopia (Scott et al., 2003), these findings are in stark contrast to the sedentary lifestyles of young Scottish children (Reilly et al., 2004) and the increasing prevalence of childhood obesity in the USA and UK (Ebbeling, Pawlak, \& Ludwig, 2002). Athletes also differed from controls in their method of travel to school, with a higher proportion of athletes running to school each day [controls $22 \%$; national athletes $73 \%(P<0.001)$; international athletes $82 \%(P<0.001)$ ]. It was not possible to assess whether the elite athletes ran to school because of the greater distances they had to travel or because they were naturally able to do so with greater ease than the controls. When participants who had travelled equivalent distances (i.e. $>5 \mathrm{~km}$ ) were compared between groups, $86 \%$ of international athletes and $77 \%$ of national athletes ran to school compared with only $23 \%$ of controls (controls vs. national athletes: $\chi^{2}=35.2, P<0.001$; controls vs. international athletes: $\chi^{2}=28.5, P<$ 0.001). When participants using other means of getting to school, such as a bicycle or motorized transport, were excluded from all three groups, the differences in running to school between groups remained, with $50 \%$ of controls, $84 \%$ of national and $91 \%$ of international athletes running to school (controls vs. national athletes: $\chi^{2}=7.10, P=0.008$; controls vs. international athletes: $\chi^{2}=10.39$, $P=0.001)$. Although based on only a few control participants with whom to compare the athletes, the finding that when travelling equivalent distances a higher proportion of athletes chose to run, raises the interesting question of whether these athletes were inherently more able to cover these large distances to and from school each day by running. Regardless of the reasons for running such long distances to school, this amount of exercise each day would undoubtedly lead to training adaptations for distance running.

A considerable proportion of national and international athletes were motivated to run for economic reasons (Figure 7). Thirty-eight percent of the national and $33 \%$ of the international runners became athletes for economic empowerment. It is estimated that $40 \%$ of the total Kenyan population are unemployed and at least $50 \%$ live below the poverty line. It would stand to reason, therefore, that economic reasons would act as an important contributing factor to the success of East African athletes in distance running, a factor not accounted for in any other studies to date.

\section{Conclusions}

The results of this study suggest that elite Kenyan athletes have a distinct ethnic and environmental background compared with the general Kenyan population. Athletes differed from controls in all variables considered. The majority of Kenyan runners were from the Rift Valley province, are Kalenjin and spoke languages of Nilotic origin. Athletes also travelled farther to school than controls and mainly did so by running. International athletes tended to show a pronounced version of this profile compared with national athletes. These results suggest the importance of such environmental factors in the success of elite Kenyan distance runners.

\section{Acknowledgements}

The authors acknowledge the invaluable assistance of Athletics Kenya. Heather Collin is acknowledged for her excellent technical assistance. The cooperation of all participants is also greatly appreciated.

\section{References}

Baker, J., \& Horton, S. (2003). East African running dominance revisited: A role for stereotype threat? British fournal of Sports Medicine, 37, 553-555.

Bosch, A. N., Goslin, B. R., Noakes, T. D., \& Dennis, S. C. (1990). Physiological differences between black and white runners during a treadmill marathon. European fournal of Applied Physiology and Occupational Physiology, 61, 68-72.

Coetzer, P., Noakes, T. D., Sanders, B., Lambert, M. I., Bosch, A. N., Wiggins, T. et al. (1993). Superior fatigue resistance of elite black South African distance runners. Fournal of Applied Physiology, 75, $1822-1827$.

Ebbeling, C. B., Pawlak, D. B., \& Ludwig, D. S. (2002). Childhood obesity: Public-health crisis, common sense cure. Lancet, 360(9331), 473-482.

Entine, J. (2001). Race and sport. The race to the swift - if the swift have the right ancestry. Peak Performance (Special Issue: Race and Genetics), 158, 1-6.

Gayagay, G., Yu, B., Hambly, B., Boston, T., Hahn, A., Celermajer, D. S. et al. (1998). Elite endurance athletes and the ACE I allele - the role of genes in athletic performance. Human Genetics, 103, 48-50.

Kenyan Central Bureau of Statistics (2003). Statistical abstract. Nairobi: Ministry of Planning and National Development.

Larsen, H. B. (2003). Kenyan dominance in distance running. Comparative Biochemistry and Physiology A: Molecular and Integrative Physiology, 136, 161-170.

Manners, J. (1997). Kenya's running tribe. The Sports Historian, 17(2), 14-27.

Pkalya, P., \& Aden, M. (2003). Conflicts in Kenya. Nairobi: ITDG.

Reilly, J. J., Jackson, D. M., Montgomery, C., Kelly, L. A., Slater, C., Grant, S. et al. (2004). Total energy expenditure and physical activity in young Scottish children: mixed longitudinal study. Lancet, 363 (9404), 211-212.

Saltin, B. (1996). Exercise and the environment: Focus on altitude. Research Quarterly for Exercise and Sport, 67(suppl.), $\mathrm{S} 1-\mathrm{S} 10$.

Saltin, B., Larsen, H., Terrados, N., Bangsbo, J., Bak, T., Kim, C. K. et al. (1995). Aerobic exercise capacity at sea level and at altitude in Kenyan boys, junior and senior runners compared with Scandinavian runners. Scandinavian fournal of Medicine and Science in Sports, 5, 209-221. 
Schmidt, W., Heinicke, K., Rojas, J., Manuel, G. J., Serrato, M., Mora, M. et al. (2002). Blood volume and hemoglobin mass in endurance athletes from moderate altitude. Medicine and Science in Sports and Exercise, 34, 1934-1940.

Scott, R. A., Georgiades, E., Wilson, R. H., Goodwin, W. H., Wolde, B., \& Pitsiladis, Y. P. (2003). Demographic characteristics of elite Ethiopian endurance runners. Medicine and Science in Sports and Exercise, 35, 1727-1732.

Weston, A. R., Karamizrak, O., Smith, A., Noakes, T. D., \& Myburgh, K. H. (1999). African runners exhibit greater fatigue resistance, lower lactate accumulation, and higher oxidative enzyme activity. Fournal of Applied Physiology, 86, 915-923.
Weston, A. R., Mbambo, Z., \& Myburgh, K. H. (2000) Running economy of African and Caucasian distance runners. Medicine and Science in Sports and Exercise, 32, $1130-1134$.

Yang, N., MacArthur, D. G., Gulbin, J. P., Hahn, A. G., Beggs, A. H., Easteal, S. et al. (2003). ACTN3 genotype is associated with human elite athletic performance. American fournal of Human Genetics, 73, 627-631.

Yu, N., Chen, F. C., Ota, S., Jorde, L. B., Pamilo, P., Patthy, L. et al. (2002). Larger genetic differences within Africans than between Africans and Eurasians. Genetics, 161, 269274 . 